\title{
Severity of Periodontitis and Metabolic Syndrome: Is There an Association?
}

Isaac Suzart Gomes-Filho, * Magno Conceição das Mercês, * Johelle de Santana Passos-Soares, *† Simone Seixas da Cruz, ${ }^{*}{ }^{\ddagger}$ Ana Marice Teixeira Ladeia,§ Soraya Castro Trindade, ${ }^{*}$ Eneida de Moraes Marcílio Cerqueira, * Julita Maria Freitas Coelho,ll Fernanda Maria Marques Monteiro, * Maurício Lima Barreto, "I Maria Isabel Pereira Vianna, ${ }^{\dagger}$ Maria da Conceição Nascimento Costa," "l Gregory John Seymour," and Frank A. Scannapieco**

Background: Metabolic syndrome (MetS) is a major factor for the occurrence of cardiovascular events. Causal factors for MetS are not well defined or yet unidentified. Preliminary investigations suggest that infections and inflammation may be involved in the etiology of this syndrome. This study aims to estimate the association between the severity of periodontitis (exposure) and MetS (outcome).

Methods: A cross-sectional study was conducted with 419 participants recruited from the Diabetes and Hypertensive Treatment Center, Feira de Santana, Bahia, Brazil. After administration of a questionnaire, general and oral clinical examination and laboratory tests were performed. Diagnosis of periodontitis and MetS was performed according to various criteria. The analysis of the effect of periodontitis on MetS used logistic regression analysis with adjustment for confounders.

Results: The prevalence of periodontitis was found to be between $34.61 \%$ and $55.37 \%$, depending on the classification definitions used, and the prevalence of MetS ranged from $60.86 \%$ to $67.06 \%$. In the group with periodontitis, $14.08 \%$ had severe and $41.29 \%$ had moderate levels of periodontitis. There was an association between severe periodontitis and MetS after adjustment for sex, age, household density, alcoholic beverage consumption, smoking habit, and cardiovascular disease (odds ratio OR $\mathrm{R}_{\text {adjusted_6 }}=2.11,95 \%$ confidence interval $=1.01$ to $4.40, P=0.05$ ).

Conclusions: The results suggest that periodontitis is associated with MetS, and that MetS prevalence is related to severe periodontitis. J Periodontol 2016;87:357-366.

\section{KEY WORDS}

Epidemiology; metabolic syndrome X; periodontitis.

\footnotetext{
* Department of Health, Feira de Santana State University, Feira de Santana, Bahia, Brazil . Department of Preventive Dentistry, Federal University of Bahia, Salvador, Bahia, Brazil.

† Department of Epidemiology, Federal University of Recôncavo of Bahia, Santo Antonio de Jesus, Bahia, Brazil.

§ Bahiana School of Medicine and Public Health, Bahia Foundation for the Development of Sciences, Salvador, Bahia, Brazil.

II Department of Biological Sciences, Feira de Santana State University.

II Department of Epidemiology, Public Health Institute, Federal University of Bahia.

\# Oral Molecular Immunopathology Research Group, Sir John Walsh Research Institute, Faculty of Dentistry, University of Otago, Otago, New Zealand.

* * Department of Oral Biology, University of Buffalo, Buffalo, NY.
}

$M$ etabolic syndrome (MetS) comprises a set of physiologic and physical changes that include at least three of the following: 1) abdominal obesity; 2) hypertriglyceridemia; 3) reduced high-density lipoprotein (HDL) cholesterol; 4) hypertension; and 5) impaired fasting glucose. ${ }^{1-4}$ This syndrome has been suggested as a risk factor for cardiovascular disease, the leading cause of death globally. ${ }^{5-8}$ According to the International Diabetes Federation, onequarter of the world adult population has the syndrome, with males $>40$-years-old and postmenopausal females having the highest risk. ${ }^{4}$

Causal factors related to the syndrome are not well defined. It is known that insulin resistance plays a role in its etiology. 4 Some findings have also implicated chronic infections and inflammation, such as periodontitis, in the etiology of MetS. ${ }^{9,10}$ Infection results in an immune inflammatory process, and thus, with the systemic dissemination of bacteria and inflammatory mediators, a chronic systemic inflammatory condition is established that may provoke or exacerbate MetS.

Additionally, recent evidence suggests that chronic inflammatory diseases not resulting from bacterial insult, such as psoriasis, and inflammatory arthritis can also increase systemic inflammation and the risk of atheromatous disease, including coronary heart disease and stroke, as well 
as insulin resistance, leading to the emergence of MetS and type 2 diabetes. ${ }^{11-13}$ The focus of research has thus shifted to understanding less well-characterized etiologic and antecedent factors, whether bacterial in origin or not, as well as measuring the effect of the exposure severity on the outcome. ${ }^{11}$

These observations may be of considerable importance for the management of individuals with chronic inflammatory diseases, such as periodontitis, whose prevalence and severity increase with age. ${ }^{14}$

Previous studies that suggested an association between periodontitis and $M S^{10,15-22}$ were heterogeneous in design; used different definitions of periodontitis, often based on partial-mouth recordings; and used only one definition of MetS. Additionally, a consensus about this relationship does not yet exist. ${ }^{23}$ Thus, in attempting to better understand this relationship, the present study extends current knowledge by using several definitions of both periodontitis (the exposure) and MetS (the outcome) as well as by providing a substantially larger sample size, allowing for the exploration of potential confounders, to determine whether an association between the severity of periodontal breakdown and MetS exists.

\section{MATERIALS AND METHODS}

\section{Study Design and Sample}

A cross-sectional study was conducted of 419 adults recruited from the Diabetes and Hypertensive Treatment Center in Feira de Santana, Bahia, Brazil, from June 2013 to February 2014.

The minimum size of the sample was calculated assuming a $95 \%$ confidence interval $(\mathrm{CI})$, a power of $80 \%$, ratio of $1: 1$ between exposure and non-exposure, and a MetS frequency of $16.7 \%$ for the non-exposed group and $35.3 \%$ for the exposed group. ${ }^{21}$ The minimum number of individuals required to compare exposed (individuals with periodontitis) with non-exposed was 97 each, totaling 194 individuals. To compensate for attrition and missing data, $10 \%$ more were included, totaling 214 participants in the minimum sample size.

This study was approved by the Research Ethics Committee of Feira de Santana State University, Bahia, Brazil (Protocol 302.031). All participants signed the informed consent form.

\section{Inclusion and Exclusion Criteria}

This study included individuals having the following: 1 ) aged $\geq 24$ years; 2 ) the presence of at least four teeth to ensure the measurements necessary for diagnosis of periodontal condition; and 3) laboratory measurement of triglycerides, HDL cholesterol, and fasting glucose, made in the previous 90 days before the oral and general clinical examination of the participant.
Exclusion criteria consisted of the following: 1) individuals who were pregnant; 2 ) those who received periodontal treatment in the 3 months before enrollment; 3) those who were diagnosed with cancer, human immunodeficiency virus/AIDS, or systemic, urinary, fungal, or tissue infections; and 4) those with whom verbal communication was not possible.

\section{Data Collection Procedures}

Participants answered a questionnaire to obtain data related to socioeconomic, demographic, lifestyle, health conditions, and dental history. The following results of laboratory tests were collected from the medical records: 1) triglycerides; 2) HDL cholesterol; 3) fasting glucose; 4) total cholesterol; 5) low-density lipoprotein cholesterol; 6) creatinine; 7) uric acid; 8) microalbuminuria; 9) leukocytes; 10) band cells; and 11) neutrophils. All test results from the participant's medical records were performed by the Laboratory of the Feira de Santana Municipal Health, Bahia, Brazil.

A single examiner (MCM) reviewed the medical history of the participants and conducted a physical examination, including vital signs, anthropometric measurements (weight, height, and waist circumference), palpation, and auscultations. Subsequently, a single dentist (FMMM) masked to the individuals' medical status conducted an oral clinical examination. Reproducibility was assessed by replication of periodontal measurements. This was done using as reference an experienced periodontist (ISG-F) for $10 \%$ of the sample. The intraexaminer $\kappa$ index for the means of probing depth $(\mathrm{PD})$ and recession were, respectively, 0.77 and 0.89 . The interexaminer $\kappa$ index showed concordance rates of 0.87 and 0.85 for these measurements, respectively.

\section{Oral and General Clinical Examination}

The general clinical examination consisted of obtaining the medical history, abdominal circumference measurement, and blood pressure levels. Waist circumference was measured by the distance between the iliac crest and the lower costal margin using a $150-\mathrm{cm}$ measuring tape, with a scale of $0.5 \mathrm{~cm} .{ }^{\dagger \dagger}$ Blood pressure was obtained in duplicate, repeated 5 minutes after the first measurement, in a quiet environment, and with proper positioning of the individual using a stethoscope ${ }^{\ddagger \ddagger}$ and a sphygmomanometer,,$\S$ calibrated 1 week before the beginning of the study. ${ }^{24}$ The body mass index (BMI) was calculated from weight and height measurements. ${ }^{24}$

The oral clinical examination assessed the presence of teeth, caries, and restorations. Furthermore, periodontal status was investigated on all teeth except

\footnotetext{
$\dagger \dagger$ Instituto São Paulo, Santa Tereza Do Oeste, Paraná, Brazil.

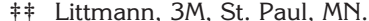

$\S \S$ BD Biosciences, Franklin Lakes, NJ.
} 
the third molars. The following clinical parameters were obtained using a Williams probe $\left.\right|^{|l| \mid}$ : PD, recession measurement, clinical attachment level (CAL), and bleeding on probing (BOP).

$\mathrm{PD}^{25}$ was measured as the distance from the gingival margin to the most apical depth of the pocket at six sites per tooth (mesio-buccal, mid-buccal, distobuccal, mesio-lingual, mid-lingual, and disto-lingual). In the same six sites, measurements of $\mathrm{BOP},{ }^{26}$ recession, and CAL were obtained. ${ }^{27}$ Recession was measured as the distance between the gingival margin and the cemento-enamel junction (CEJ), and CAL was measured as the distance from the CEJ to the base of the pocket. The visible plaque index (PI) was also evaluated using the same probe in four sites per tooth (buccal, lingual, mesial, and distal) measured as the presence of visible biofilm deposit on the tooth surface.

\section{Diagnosis of Periodontitis}

Participants were diagnosed as having periodontitis (group with periodontitis) if they had at least four teeth with at least one site with a PD $\geq 4 \mathrm{~mm}$, CAL $\geq 3 \mathrm{~mm}$, and BOP at the same site. ${ }^{28}$ Those participants who did not meet these criteria were considered not to have periodontitis (group with no periodontitis).

Participants were also classified with severe periodontitis if they had at least two interproximal sites with CAL $\geq 6 \mathrm{~mm}$ (not affecting the same tooth) and at least one interproximal site with $P D \geq 5 \mathrm{~mm}$. The moderate periodontitis (group with moderate periodontitis) was defined as having at least two interproximal sites with CAL $\geq 4 \mathrm{~mm}$ (not on same tooth) or at least two interproximal sites with PD $\geq 5$ $\mathrm{mm}$ (not on the same tooth). ${ }^{29}$

\section{Diagnosis of MetS}

The diagnosis of MetS was based on two case definitions: 1) National Cholesterol Education Program's Adult Treatment Panel III (NECP) ${ }^{2}$ and 2) International Diabetes Federation (IDF). ${ }^{30}$ Participants diagnosed with MetS had at least three of the criteria shown in Table 1.

\section{Statistical Analyses}

Descriptive analysis was undertaken of the independent variable, periodontitis, and all covariables considered for the study. Simple frequencies and measurements of central tendency were obtained, and statistical differences were evaluated using the Pearson $\chi^{2}$ test for categorical variables and $t$ test for continuous variables, with a significance level of $P=0.05$.

The analysis of the effect of periodontitis on MetS was initially performed using bivariate, stratified analysis, and, subsequently, logistic regression analysis was applied
Table I.

\section{MetS Diagnostics According to the NCEP $^{2}$ and IDF $^{30}$ Criteria}

\begin{tabular}{ll}
\hline Components & \multicolumn{1}{c}{ Reference Levels } \\
\hline $\begin{array}{l}\text { Abdominal obesity by } \\
\text { abdominal circumference }\end{array}$ & $>102 \mathrm{~cm}^{2}$ \\
Males & $>94 \mathrm{~cm}^{30}$ \\
European males & $>90 \mathrm{~cm}^{30}$ \\
Asian males & $>88 \mathrm{~cm}^{2}$ or $>80 \mathrm{~cm}^{30}$ \\
Females & $\geq 150 \mathrm{mg} / \mathrm{dL}^{30}$ \\
Triglycerides & \\
HDL cholesterol & $<40 \mathrm{mg} / \mathrm{dL}^{2,30}$ \\
Males & $<50 \mathrm{mg} / \mathrm{dL}^{2,30}$ \\
Females & $\geq 130 \mathrm{mmH} g^{2,30}$ \\
Arterial pressure & $\geq 85 \mathrm{mmHg} \mathrm{g}^{2,30}$ \\
Systolic & $\geq 110 \mathrm{mg} / \mathrm{dL}^{2}$ or $\geq 100 \mathrm{mg} / \mathrm{dL}^{30}$ \\
\hline Diastolic &
\end{tabular}

using six analysis models in accordance with the diagnosis of MetS (NECP and IDF) 2,30 and periodontitis (presence of periodontitis, ${ }^{28}$ severe periodontitis, and moderate periodontitis ${ }^{29}$ ), estimated by odds ratio (OR) and $95 \%$ Cls.

The presence of effect modifiers was investigated using the maximum likelihood ratio test $(P<0.05)$ by comparing models with and without the product terms. For variables in which the presence of effect modification was not empirically identified, the role of confounding covariables was evaluated by means of a backward strategy, when the covariable produced a relative difference of $10 \%$ of the association measurement in reference to the saturated model. Besides the statistical confirmation, theoretical knowledge on the role of covariables influencing both the exposure and the outcome was used to choose confounders that were included in the final analysis model. The data were analyzed using a statistical program.

\section{RESULTS}

A total of 419 participants (160 males and 259 females, age range 24 to 89 years; mean \pm SD age: $59 \pm$ 13.3 years) were enrolled in this study. From these, 255 (60.86\%) individuals were diagnosed with MetS according to the criterion of the $\mathrm{NECP}^{2}$ (81 males [31.80\%] and 174 females [68.20\%]) but 281 (67.06\%) individuals according to the IDF ${ }^{30}$ criterion (95 males [33.80\%] and 186 females [66.20\%]). The prevalence

|l|| Hu-Friedy, Chicago, IL.

II Stata v.9.0, StataCorp, College Station, TX. 
Table 2.

Socioeconomic-Demographic and Lifestyle Characteristics of the Sample in Accordance With Periodontitis Diagnosis $(\mathrm{N}=419)$

\begin{tabular}{|c|c|c|c|}
\hline Characteristics & \multicolumn{2}{|c|}{ Periodontitis, n (\%) } & $P$ Value* \\
\hline $\begin{array}{l}\text { Age (years) } \\
\leq 59 \\
>59\end{array}$ & $\begin{array}{l}70(48.3) \\
75(51.7)\end{array}$ & $\begin{array}{l}138(50.4) \\
136(49.6)\end{array}$ & 0.68 \\
\hline $\begin{array}{l}\text { Sex } \\
\text { Males } \\
\text { Females }\end{array}$ & $\begin{array}{l}64(44.1) \\
81(55.9)\end{array}$ & $\begin{array}{r}96(35.0) \\
178(65.0)\end{array}$ & 0.07 \\
\hline $\begin{array}{l}\text { Race/skin color }{ }^{\dagger} \\
\text { White } \\
\text { Non-white }\end{array}$ & $\begin{array}{l}40(32.5) \\
83(67.5)\end{array}$ & $\begin{array}{r}65(26.9) \\
177(73.1)\end{array}$ & 0.26 \\
\hline $\begin{array}{l}\text { Marital status }{ }^{\dagger} \\
\text { With partner } \\
\text { Without partner }\end{array}$ & $\begin{array}{l}72(50.0) \\
72(50.0)\end{array}$ & $\begin{array}{l}126(46.0) \\
148(54.0)\end{array}$ & 0.43 \\
\hline $\begin{array}{l}\text { Family income (minimum salary) } \\
<\text { I minimum salary } \\
\text { I minimum salary } \\
\geq 2 \text { minimum salaries }\end{array}$ & $\begin{array}{l}37(26.1) \\
50(35.2) \\
55(38.7)\end{array}$ & $\begin{array}{r}65(25.1) \\
117(45.2) \\
77(29.7)\end{array}$ & 0.11 \\
\hline $\begin{array}{l}\text { Place of residence }{ }^{\dagger} \\
\text { Urban } \\
\text { Rural }\end{array}$ & $\begin{array}{r}120(83.9) \\
23(16.1)\end{array}$ & $\begin{array}{r}233(87.9) \\
32(12.1)\end{array}$ & 0.26 \\
\hline $\begin{array}{l}\text { Household density }^{\dagger} \\
\leq 3 \text { persons } \\
>3 \text { persons }\end{array}$ & $\begin{array}{l}78(53.8) \\
67(46.2)\end{array}$ & $\begin{array}{l}168(62.0) \\
103(38.0)\end{array}$ & 0.11 \\
\hline $\begin{array}{l}\text { Physical activity practice }{ }^{\dagger} \\
\text { No } \\
\text { Yes }\end{array}$ & $\begin{array}{l}95(65.5) \\
50(34.5)\end{array}$ & $\begin{array}{l}167(62.1) \\
102(37.9)\end{array}$ & 0.49 \\
\hline $\begin{array}{l}\text { Last visit to dentist }{ }^{\dagger} \\
\quad \leq 1 \text { year } \\
\geq 2 \text { years }\end{array}$ & $\begin{array}{l}17(18.3) \\
76(81.7)\end{array}$ & $\begin{array}{r}44(23.8) \\
|4|(76.2)\end{array}$ & 0.29 \\
\hline $\begin{array}{l}\text { Periodic visit to dentist }{ }^{\dagger} \\
\text { Yes } \\
\text { No }\end{array}$ & $\begin{array}{c}138(95.8) \\
6(4.2)\end{array}$ & $\begin{array}{c}249(91.9) \\
22(8.1)\end{array}$ & 0.13 \\
\hline $\begin{array}{l}\text { Dental floss usage }{ }^{\dagger} \\
\text { Yes } \\
\text { No }\end{array}$ & $\begin{array}{l}59(40.7) \\
86(59.3)\end{array}$ & $\begin{array}{l}109(40.5) \\
160(59.5)\end{array}$ & 0.97 \\
\hline
\end{tabular}

* $P \leq 0.05$.

† Data not available for all participants.

† Minimum salary value at the time of data collection: R\$678,00 (US \$288.51). 
Table 3.

Characteristics Related to General Health and Laboratorial Condition of the Sample in Accordance With Periodontitis Diagnosis ( $\mathrm{N}=419)$

\begin{tabular}{|c|c|c|c|}
\hline \multirow[b]{2}{*}{ Characteristics } & \multicolumn{2}{|c|}{ Periodontitis, n (\%) } & \multirow[b]{2}{*}{$P$ Value* } \\
\hline & Yes $(n=145)$ & No $(n=274)$ & \\
\hline MetS NECP² & & & 0.79 \\
\hline No & $58(40.00)$ & $106(38.70)$ & \\
\hline Yes & $87(60.00)$ & $168(61.30)$ & \\
\hline MetS IDF 30 & & & 0.48 \\
\hline No & $51(35.20)$ & $87(31.80)$ & \\
\hline Yes & $94(64.80)$ & $187(68.20)$ & \\
\hline Diabetes $^{\dagger}$ & & & 0.99 \\
\hline No & $17(11.70)$ & $32(11.80)$ & \\
\hline Yes & $128(88.30)$ & $240(88.20)$ & \\
\hline Cardiovascular disease $^{\dagger}$ & & & 0.05 \\
\hline No & $128(90.10)$ & $226(83.10)$ & \\
\hline Yes & $14(9.90)$ & $46(16.90)$ & \\
\hline Liver disease $^{\dagger}$ & & & 0.97 \\
\hline No & $59(40.70)$ & $109(40.50)$ & \\
\hline Yes & $86(59.30)$ & $160(59.50)$ & \\
\hline Respiratory disease $^{\dagger}$ & & & 0.43 \\
\hline No & $142(97.90)$ & $270(98.90)$ & \\
\hline Yes & $3(2.10)$ & $3(1.10)$ & \\
\hline Renal disease $^{\dagger}$ & & & 0.17 \\
\hline No & $136(94.40)$ & $241(90.60)$ & \\
\hline Yes & $8(5.60)$ & $25(9.40)$ & \\
\hline Hypertension ${ }^{\dagger}$ & & & 0.32 \\
\hline No & $54(37.20)$ & $88(32.40)$ & \\
\hline Yes & $91(62.80)$ & $184(67.60)$ & \\
\hline Use of antihypertensive medication ${ }^{\dagger}$ & & & 0.19 \\
\hline No & $33(24.10)$ & $77(30.30)$ & \\
\hline Yes & $104(75.90)$ & $177(69.70)$ & \\
\hline $\mathrm{BMI}\left(\mathrm{kg} / \mathrm{m}^{2}\right)^{\dagger}$ & & & 0.98 \\
\hline$<25$ & $103(80.50)$ & $186(81.20)$ & \\
\hline 25 to $<30$ & $20(15.60)$ & $34(14.80)$ & \\
\hline$\geq 30$ & $5(3.90)$ & $9(3.90)$ & \\
\hline Abdominal obesity ( $\geq 102 \mathrm{~cm}$ males; $\geq 88 \mathrm{~cm}$ females) ${ }^{\dagger}$ & & & 0.17 \\
\hline No & $97(67.80)$ & $166(61.00)$ & \\
\hline Yes & $46(32.20)$ & $106(39.00)$ & \\
\hline Triglycerides $(\mathrm{mg} / \mathrm{dL})^{\dagger}$ & & & 0.13 \\
\hline$<150$ & $81(57.00)$ & $172(64.70)$ & \\
\hline$\geq 150$ & $61(43.00)$ & $94(35.30)$ & \\
\hline $\begin{array}{l}\mathrm{HDL} \text { cholesterol }(<40 \mathrm{mg} / \mathrm{dL} \text { males; }<50 \mathrm{mg} / \mathrm{dL} \\
{\text { females })^{\dagger}}^{\text {a }}\end{array}$ & & & 0.09 \\
\hline No & $82(58.20)$ & $132(49.30)$ & \\
\hline Yes & $59(41.80)$ & $136(50.70)$ & \\
\hline
\end{tabular}


Table 3. (continued)

\section{Characteristics Related to General Health and Laboratorial Condition of the Sample in Accordance With Periodontitis Diagnosis ( $\mathrm{N}=419)$}

\begin{tabular}{|c|c|c|c|}
\hline \multirow[b]{2}{*}{ Characteristics } & \multicolumn{2}{|c|}{ Periodontitis, n (\%) } & \multirow[b]{2}{*}{$P$ Value* } \\
\hline & Yes $(n=145)$ & No $(n=274)$ & \\
\hline Systolic blood pressure $(\mathrm{mmHg})$ & & & 0.02 \\
\hline$<130$ & $43(29.70)$ & $112(40.90)$ & \\
\hline$\geq 130$ & $102(70.30)$ & $162(59.10)$ & \\
\hline Diastolic blood pressure $(\mathrm{mmHg})$ & & & 0.20 \\
\hline$<85$ & $73(50.30)$ & $156(56.90)$ & \\
\hline$\geq 85$ & $72(49.70)$ & $118(43.10)$ & \\
\hline Fasting glucose $(\mathrm{mg} / \mathrm{dL})^{\dagger}$ & & & 0.93 \\
\hline$<110$ & $41(29.10)$ & $78(29.70)$ & \\
\hline$\geq 110$ & $100(70.90)$ & $185(70.30)$ & \\
\hline
\end{tabular}

*P $\leq 0.05$.

$\dagger$ Data not available for all participants.

of periodontitis was found to be between $34.61 \%^{28}$ and $55.37 \%,{ }^{29}$ depending on the classification definitions used. In the group with periodontitis (Page and Eke criteria $)^{29}$, levels were severe in $14.08 \%$ and moderate in $41.29 \%$.

Table 2 shows the socioeconomic, demographic, and lifestyle characteristics of the participants, with and without periodontitis. No statistically significant differences were noted between the groups for any of the variables measured.

For characteristics related to general health and laboratory values, only cardiovascular disease $(P=0.05)$ and systolic blood pressure $(P=0.02)$ showed statistically significant differences between the groups of individuals with and without periodontitis (Table 3). The prevalence of self-reported cardiovascular disease was higher in the group without periodontitis $(16.9 \%)$ than in the group with periodontitis (9.9\%), and the frequency of systolic blood pressure $\geq 130 \mathrm{mmHg}$ was higher in the periodontitis group $(70.3 \%)$ than in the non-periodontitis group (59.1\%).

Table 4 presents the oral health clinical measurements in accordance with the diagnosis of periodontitis. As expected, the mean PD measurements, CAL, BOP index, and visible PI were statistically greater $(P<0.001)$ in the periodontitis group compared with the non-periodontitis group.

Comparison of measurements between periodontitis and MetS are shown in Table 5. Models 1, 3, and 5 used the NECP criteria, ${ }^{2}$ whereas Models 2,4 , and 6 used the IDF criteria. ${ }^{30}$ According to the crude ORs for the six models investigated, the presence of periodontitis and its level of severity were not an independent factor for MetS (Table 5).
Neither effect-modified covariables nor confounders were identified in the stratified and multivariable analyses. However, sex, age, household density, alcoholic beverage consumption, smoking habit, and cardiovascular disease were used in the models for adjustment, given the epidemiologic relevance for the association under study, influencing both the exposure and the outcome. The adjusted measurement for the association between severe periodontitis and MetS showed MetS to be 2.11 times more prevalent in the group with periodontal infection than in the non-periodontitis group $\left(\mathrm{OR}_{\text {adjusted_6 }}=2.11,95 \% \mathrm{Cl}=1.01\right.$ to $\left.4.40, P=0.05\right)$ after adjustment.

\section{DISCUSSION}

The main findings of this study suggest that there is an association between severe periodontitis and MetS, after adjusting for confounding covariables such as sex, age, household density, alcoholic beverage consumption, smoking habit, and cardiovascular disease. These findings support previous studies that described an association between periodontitis and MetS, ${ }^{8,15-19,31-34}$ with the exception of one study that did not find such an association. ${ }^{23}$

Periodontitis may predispose individuals to MetS through mechanisms triggered by the translocation of oral bacteria and/or their products into the blood circulation. These bacteria may then provoke immune and inflammatory processes that initiate or exacerbate MetS. ${ }^{9,10}$

Although the mechanism that explains this connection is not well defined, recently Dregan et al. ${ }^{11}$ provided population-level estimates that clearly show that a wide range of chronic inflammatory diseases that do not involve a prominent bacterial component 
Table 4.

Oral Condition of the Sample in Accordance With Periodontitis Diagnosis $(\mathrm{N}=419)$

\begin{tabular}{|c|c|c|c|}
\hline \multirow[b]{2}{*}{ Characteristics } & \multicolumn{2}{|c|}{ Periodontitis } & \multirow[b]{2}{*}{$P$ Value* } \\
\hline & Yes $(n=145)$ & No $(n=274)$ & \\
\hline \multicolumn{3}{|l|}{ PD (mm) } & \multirow[t]{3}{*}{$<0.001$} \\
\hline Mean \pm SD & $2.9 \pm 1.5$ & $2.0 \pm 1.1$ & \\
\hline Range & 0.0 to 8.2 & 0.0 to 8.2 & \\
\hline \multicolumn{3}{|l|}{ CAL (mm) } & \multirow[t]{3}{*}{$<0.001$} \\
\hline Mean \pm SD & $4.5 \pm 1.8$ & $3.1 \pm 1.1$ & \\
\hline Range & 0.0 to 17.5 & 0.0 to 17.5 & \\
\hline \multicolumn{3}{|l|}{$\mathrm{BOP}$ index $(\%)^{\dagger}$} & \multirow[t]{3}{*}{$<0.001$} \\
\hline Mean \pm SD & $67.3 \pm 29.7$ & $25.0 \pm 25.5$ & \\
\hline Range & 0.0 to 100.0 & 0.0 to 100.0 & \\
\hline & \multirow[t]{3}{*}{$<0.001$} \\
\hline Mean \pm SD & $35.6 \pm 40.1$ & $21.1 \pm 30.0$ & \\
\hline & 0.0 to 100.0 & 0.0 to 100.0 & \\
\hline & \multirow[t]{3}{*}{0.69} \\
\hline Mean \pm SD & $13.3 \pm 7.1$ & $13.0 \pm 7.1$ & \\
\hline Range & 4 to 28 & 4 to 28 & \\
\hline \multicolumn{3}{|l|}{ CAL $\geq 3 \mathrm{~mm}(\mathrm{n}, \%)$} & \multirow[t]{3}{*}{0.14} \\
\hline$<4$ teeth & 0 & $4(1.5)$ & \\
\hline$\geq 4$ teeth & $145(100.0)$ & $270(98.5)$ & \\
\hline \multicolumn{3}{|l|}{ CAL $\geq 5 \mathrm{~mm}(\mathrm{n}, \%)$} & \multirow[t]{3}{*}{$<0.00$ I } \\
\hline$<30 \%$ teeth & II (7.6) & $142(5 \mid .8)$ & \\
\hline$\geq 30 \%$ teeth & $134(92.4)$ & $132(48.2)$ & \\
\hline \multicolumn{3}{|l|}{$P D \geq 4 \mathrm{~mm}(\mathrm{n}, \%)$} & \multirow[t]{3}{*}{$<0.00$ I } \\
\hline$<4$ teeth & $8(5.5)$ & $260(94.9)$ & \\
\hline$\geq 4$ teeth & $137(94.5)$ & $14(5.1)$ & \\
\hline
\end{tabular}

* $P \leq 0.05$.

can raise systemic inflammation and increase the risk of cardiovascular diseases and diabetes, with evidence that the risk is associated with the severity of inflammation, which supports a direct connection between increased inflammation and MetS.

The magnitude of the association noted between periodontitis and MetS in previous studies $8,15-22,31-34$ seems to be affected by the use of multiple clinical criteria to ascertain the severity of periodontal disease. Only three reports ${ }^{15,22,32}$ have found an association between severe periodontitis and MetS, as observed in the present study. It is possible that more severe chronic inflammation increases the risk for MetS.

It must be emphasized that the criterion to classify the level of severity of periodontitis in this study uses a very conservative case definition of periodontitis, based on the definitions endorsed by the American Academy of Periodontology. ${ }^{29}$ Previously, D'Aiuto et al. ${ }^{15}$ used this classification based on partial-mouth recordings. However, the present study defined the periodontal disease based on a full-mouth clinical examination, strengthening its findings, because partial recordings increase the chance of misclassification.

Similarly, the diagnosis of MetS was performed by the use of two internationally recognized criteria, NCEP and IDF, 2,30 because there is not a consensus as to the best criterion to be used for this purpose.

Despite statistical tests not finding the presence of confounding variables in this study, additional care was taken in the method to reduce the interference of covariables that may influence both periodontitis and MetS. Thus, the covariables sex, age, household density, alcoholic beverage consumption, smoking habit, and cardiovascular disease were kept in the six final adjusted analysis models.

For example, it is known that the prevalence of periodontitis increases with advancing age, ${ }^{11,15}$ as does the prevalence of MetS. ${ }^{6,15}$ The diseases occur more in males. ${ }^{6,11,15}$ Smoking and alcoholic beverage 
Table 5.

\section{Crude and Adjusted OR and 95\% CI for the Association Between Periodontitis and MetS $(\mathrm{N}=419)$}

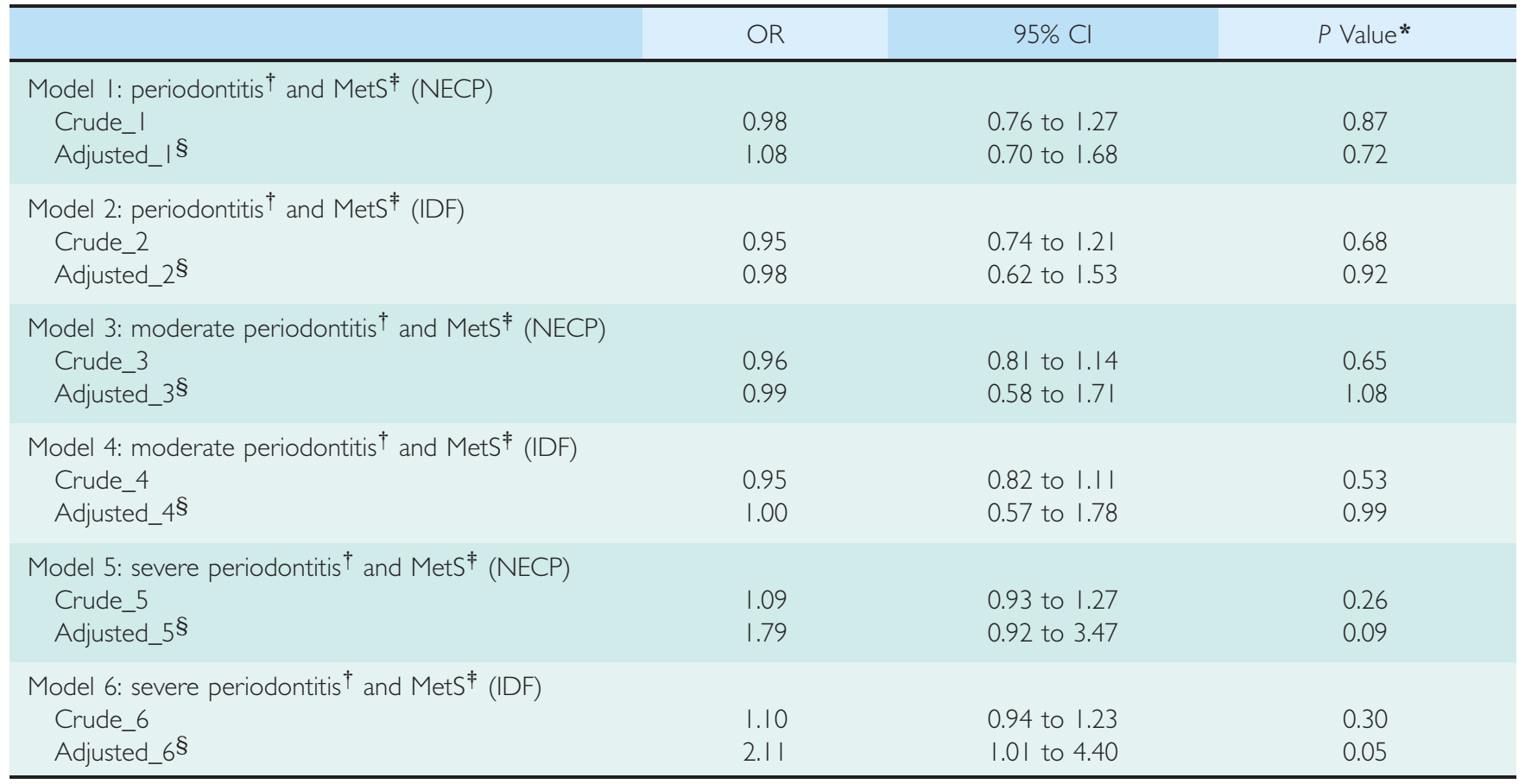

* $P \leq 0.05$.

$\dagger$ Periodontitis diagnosis: models 1 and $2 ;{ }^{28}$ models 3 and 4 , moderate periodontitis; ${ }^{29}$ models 5 and 6 , severe periodontitis. ${ }^{29}$

$\ddagger$ MetS diagnosis: models 1,3 , and $5, \mathrm{NECP}{ }^{2}$ models 2,4 , and 6 , IDF. 30

$\S$ Adjusted for sex, age, household density, alcoholic beverage consumption, smoking habit, and cardiovascular disease.

consumption are also well-recognized risk factors for both periodontitis ${ }^{11,35,36}$ and MetS. ${ }^{15,37}$ Household density covariable represented the socioeconomic conditions of the participants, ${ }^{38}$ a characteristic related to the multicausality of the diseases. An interesting finding of the present study is an inverse association between periodontitis and cardiovascular disease, which is in contrast to the prevailing evidence. However, this may be explained by the fact that individuals with cardiovascular disease may behave differently regarding health care when compared with those without the disease. Patients with cardiovascular disease were under the care of a multidisciplinary public health service team and hence appeared to control their periodontal conditions better than the group without cardiovascular disease. Thus, the negative association found may be spurious and without a causal relationship. This may account for the behavior of other covariables in the present study, such as smoking habit and diabetes.

Conversely, other covariables, such as diabetes, hypertension, and obesity, were not added to the final adjusted model confounders, because these covariables were considered as main covariables of the study. ${ }^{38}$ For the definition of the outcome variable
(MetS), a combination of components (Table 1) was used, among them, fasting glucose, which reflects diabetes status; abdominal circumference, which reflects abdominal obesity; and arterial pressure, which contributes to hypertension, were included.

Of course, other factors that could be associated with both periodontitis and MetS, for example, genetic factors, likely also play a role. Additionally, one cannot exclude the possibility of a spurious association between the conditions attributable to residual confounding, i.e., other unmeasured confounding factors.

Another limitation of the present investigation is the cross-sectional study design, which precludes determination of the temporal relationship of the disease, as well as any inference as to the direction of a potential causal pathway.

Nevertheless, the present study adds considerably to current knowledge on the topic by the inclusion of different parameters to define the exposure (presence ${ }^{28}$ and severity ${ }^{29}$ of periodontitis) and the outcome (NCEP ${ }^{2}$ and IDF ${ }^{30}$ MetS criteria) and as such strengthens confidence in the association. Moreover, a substantially larger sample size was used compared with previous studies, ${ }^{16,21,22}$ thus allowing a more robust exploration of potential confounders. 
Finally, the finding that severe periodontitis was associated with MetS, although the mere presence of periodontitis was not, may be due to several factors. The study may not have had sufficient power to detect these associations or it is possible that the definitions of periodontitis severity used were below a threshold level of exposure beyond which the association with MetS may increase steeply: 1) the specificity of the definition criterion for severe periodontitis; and 2) the sensitivity of that one used for diagnosis of presence of periodontitis and its moderate level.

Unfortunately, in the present study, a marker of systemic inflammation was not available, and hence an association among periodontal disease, systemic inflammation, and MetS could not be confirmed. Nonetheless, Dregan et al. ${ }^{11}$ demonstrated an apparent positive dose-response relationship between C-reactive protein, the severity of the exposure factor (chronic inflammatory diseases), and the risk of the outcomes (coronary heart disease, stroke, and type 2 diabetes). In this study, severe psoriasis is associated with higher rates of type 2 diabetes and coronary heart disease events in relation to mild psoriasis.

\section{CONCLUSIONS}

The present investigation suggests that severe periodontitis might influence MetS, but the observational nature of the study precludes any definitive conclusion regarding causality or mechanism. Additional studies with robust method and larger samples must be developed to solve some issues still not clarified. Considering the increase in life expectancy, the increase in tooth survival as people age, and the recent findings that support the hypothesis that any source of chronic inflammation is associated with cardiovascular disease and diabetes, leading to the emergence of the MetS, ${ }^{11}$ attention must be paid to this association to determine whether periodontal prevention/management could prevent MetS.

\section{ACKNOWLEDGMENTS}

The authors thank the State University of Feira de Santana, the Integrated Practice and Multidisciplinary Research Center, and the professionals and users of the Diabetic and Hypertensive Service Center of Feira de Santana Research Support Foundation of the State of Bahia, the National Council for Scientific and Technological Development for supporting this research. The authors also thank the study participants for their contribution to this research and the students and all professionals involved in data collection. This work was supported by the Research Support Foundation of the State of Bahia, the National Council for Scientific and Technological Development, and Feira de Santana State University. The authors report no conflicts of interest related to this study.

\section{REFERENCES}

1. World Health Organization. Definition, diagnosis and classification of diabetes mellitus and its complications. Geneva: World Health Organization; 1999.

2. Executive summary of the third report of The National Cholesterol Education Program (NCEP) expert panel on detection, evaluation, and treatment of high blood cholesterol in adults (Adults Treatment Panel III). JAMA 2001;285:2486-2497.

3. Grundy SM, Cleeman JI, Merz CN, et al; National Heart, Lung, and Blood Institute; American College of Cardiology Foundation; American Heart Association. Implications of recent clinical trials for the National Cholesterol Education Program Adult Treatment Panel III guidelines. Circulation 2004;110:227-239.

4. Brazilian guideline for diagnosis and treatment of metabolic syndrome (in Portuguese). Arq Bras Cardiol 2005;84(Suppl. 1):3-28.

5. Isomaa $B$, Almgren $P$, Tuomi $T$, et al. Cardiovascular morbidity and mortality associated with the metabolic syndrome. Diabetes Care 2001;24:683-689.

6. Ford ES, Giles WH, Dietz WH. Prevalence of the metabolic syndrome among US adults: Findings from the third National Health and Nutrition Examination Survey. JAMA 2002;287:356-359.

7. Gaede P, Vedel P, Larsen N, Jensen GV, Parving HH, Pedersen O. Multifactorial intervention and cardiovascular disease in patients with type 2 diabetes. NEnql $J$ Med 2003;348:383-393.

8. Holmlund A, Hulthe J, Lind L. Tooth loss is related to the presence of metabolic syndrome and inflammation in elderly subjects: A prospective study of the vasculature in Uppsala seniors (PIVUS). Oral Health Prev Dent 2007;5:125-130.

9. Scannapieco FA. Periodontal inflammation: from gingivitis to systemic disease? Compend Contin Educ Dent 2004;25(7, Suppl 1):16-25.

10. Han DH, Shin HS, Kim MS, Paek D, Kim HD. Group of serum inflammatory markers and periodontitis-metabolic syndrome coexistence in Koreans. JPeriodontol 2012; 83:612-620.

11. Dregan A, Charlton J, Chowienczyk P, Gulliford MC. Chronic inflammatory disorders and risk of type 2 diabetes mellitus, coronary heart disease, and stroke: A population-based cohort study. Circulation 2014; 130:837-844.

12. Corrado E, Rizzo M, Coppola G, et al. An update on the role of markers of inflammation in atherosclerosis. $J$ Atheroscler Thromb 2010;17:1-11.

13. Crowson CS, Liao KP, Davis JM 3rd, et al. Rheumatoid arthritis and cardiovascular disease. Am Heart J 2013; 166:622-628.e1

14. de Macêdo TC, Costa MdaC, Gomes-Filho IS, Vianna MI, Santos CT. Factors related to periodontal disease in a rural population. Braz Oral Res 2006;20:257-262.

15. D'Aiuto F, Sabbah W, Netuveli G, et al. Association of the metabolic syndrome with severe periodontitis in a large U.S. population-based survey. JClin Endocrinol Metab 2008;93:3989-3994.

16. Li P, He L, Sha YQ, Luan QX. Relationship of metabolic syndrome to chronic periodontitis. JPeriodontol 2009; 80:541-549.

17. Kushiyama M, Shimazaki Y, Yamashita Y. Relationship between metabolic syndrome and periodontal disease in Japanese adults. J Periodontol 2009;80: 1610-1615. 
18. Morita T, Ogawa Y, Takada K, et al. Association between periodontal disease and metabolic syndrome. J Public Health Dent 2009;69:248-253.

19. Han DH, Lim SY, Sun BC, Paek D, Kim HD. The association of metabolic syndrome with periodontal disease is confounded by age and smoking in a Korean population: The Shiwha-Banwol Environmental Health Study. J Clin Periodontol 2010;37:609-616.

20. Morita T, Yamazaki Y, Mita A, et al. A cohort study on the association between periodontal disease and the development of metabolic syndrome. J Periodontol 2010;81:512-519.

21. Benguigui C, Bongard V, Ruidavets JB, et al. Metabolic syndrome, insulin resistance, and periodontitis: A crosssectional study in a middle-aged French population. J Clin Periodontol 2010;37:601-608.

22. Nesbitt MJ, Reynolds MA, Shiau H, Choe K, Simonsick EM, Ferrucci L. Association of periodontitis and metabolic syndrome in the Baltimore Longitudinal Study of Aging. Aqing Clin Exp Res 2010;22:238-242.

23. Borges PKO, Gimeno SGA, Tomita NE, Ferreira SR. Prevalence and characteristics associated with metabolic syndrome in Japanese-Brazilians with and without periodontal disease (in Portuguese). Cad Saude Publica 2007;23:657-668.

24. Barros AL. Anamnesis and Physical Examination: Diagnostic Evaluation of Nursing in Adult (in Portuguese) 1st ed. Porto Alegre: Artmed; 2008.

25. Pihlstrom BL, Ortiz-Campos C, McHugh RB. A randomized four-years study of periodontal therapy. JPeriodontol 1981;52:227-242.

26. Ainamo J, Bay I. Problems and proposals for recording gingivitis and plaque. Int Dent J 1975;25: 229-235.

27. Ramfjord SP. Indices for prevalence and indices of periodontal disease. J Periodontol 1959;30:51-59.

28. Gomes-Filho IS, Cruz SS, Rezende EJ, et al. Exposure measurement in the association between periodontal disease and prematurity/low birth weight. J Clin Periodontol 2007;34:957-963.

29. Page RC, Eke PI. Case definitions for use in populationbased surveillance of periodontitis. J Periodontol 2007; 78(7, Suppl):1387-1399.
30. IDF. The International Diabetes Federation consensus worldwide definition of metabolic syndrome, 2005. Available at: http://www.idf.org/webdata/docs/IDF_Meta_def_final.pdf. Accessed September 22, 2014.

31. Han DH, Lim S, Paek D, Kim HD. Periodontitis could be related factors on metabolic syndrome among Koreans: A case-control study. J Clin Periodontol 2012;39:30-37.

32. Fukui N, Shimazaki Y, Shinagawa T, Yamashita Y Periodontal status and metabolic syndrome in middleaged Japanese. J Periodontol 2012;83:1363-1371

33. Tu YK, D'Aiuto F, Lin HJ, Chen YW, Chien KL. Relationship between metabolic syndrome and diagnoses of periodontal diseases among participants in a large Taiwanese cohort. J Clin Periodontol 2013;40:9941000.

34. Furuta M, Shimazaki Y, Takeshita T, et al. Gender differences in the association between metabolic syndrome and periodontal disease: The Hisayama Study. $J$ Clin Periodontol 2013;40:743-752.

35. Santos CM, Gomes-Filho IS, Passos JS, Cruz SS, Goes CS, Cerqueira EM. Risk factors associated with periodontal disease in subjects seen in a public hospital in Feira de Santana, Bahia. (in Portuguese). RBSP 2011; 35(Suppl.1):87-102.

36. Susin C, Oppermann RV, Haugejorden O, Albandar JM Periodontal attachment loss attributable to cigarette smoking in an urban Brazilian population. $J$ Clin Periodontol 2004;31:951-958.

37. Lee WY, Jung CH, Park JS, Rhee EJ, Kim SW. Effects of smoking, alcohol, exercise, education, and family history on the metabolic syndrome as defined by the ATP III. Diabetes Res Clin Pract 2005;67:70-77.

38. Rothman KJ. Greenland S, Lash TL. Modern Epidemiology, 3rd ed. Philadelphia: Lippincott, Williams \& Wilkins; 2008.

Correspondence: Dr. Isaac Suzart Gomes-Filho, Avenida Getúlio Vargas, 379, Centro, Feira de Santana, Bahia, Brazil 44025-010.Fax: 55-75-3623-0661; e-mail: isuzart@ gmail.com.

Submitted June 17, 2015; accepted for publication September 29, 2015. 